\title{
PENGEMBANGAN PERANGKAT PEMBELAJARAN PROGRAM LINEAR BERBASIS MODEL PEMBELAJARAN KOOPERATIF PENDEKATAN SCIENTIFIC DENGAN MEDIA E-LEARNING
}

\author{
SIRWANTI \\ Dosen Pendidikan Matematika \\ STKIP Muhammadiyah Bone \\ E-mail: sirwanti89@gmail.com
}

\begin{abstract}
Penelitian ini bertujuan mengembangkan perangkat pembelajaran program linear berbasis model pembelajaran kooperatif pendekatan scientific dengan media e-learning yang valid, praktis dan efektif di kelas X multimedia SMKN 1 Somba Opu. Penelitian ini merupakan penelitian pengembangan. Data dikumpulkan menggunakan lembar observasi, tes, dan kuisioner respon siswa. Subyek penelitian adalah kelas X Multimedia di SMKN 1 Somba Opu. Perangkat Pembelajaran yang dikembangkan adlah buku siswa, LKS, dan PP. Proses pengembangan perangkat pembelajaran menggunakan prinsip Thiagarajan (4-D). Hasil penelitian menyimpulkan bahwa (1) Perangkat pembelajaran yang digunakan valid karena hasil validasi berada pada interval 3,5 $\leq \bar{V}<4,5$ dengan rata-rata $\bar{V}=4.1$ berarti valid dan dapat digunakan dengan revisi kecil; (2) Perangkat pembelajaran praktis karena didalamnya terdapat kategori yang dapat mengaplikasikan aktivitas pembelajaran; (3) Perangkat pembelajaran efektif karena didalamnya terdapat tiga instrumen yaitu tes hasil belajar, LKS, dan kuisioner respon siswa yang terdapat pada kriteria interval tolerasi efektif
\end{abstract}

Kata Kunci : Kooperatif, Scientific, E-learning, Program Linear

\section{PENDAHULUAN}

Matematika sebagai ilmu dasar merupakan suatu alasan pembelajaran matematika dikemas sebaik mungkin agar mudah dipahami oleh siswa.Tujuan pembelajaran matematika sebagai pembentukan sifat, pola berpikir kritis dan kreatif yang menuntut mahasiswa mengikuti perkembangan kehidupan dan teknologi.SMK Negeri1 Somba Opu sebagai Sekolah Percontohan, dimana siswa telah melewati tes dan penjaringan khusus pada pendaftaran siswa baru sehingga secara umum siswa telah biasa mengoperasikan komputer dan internet. Pembelajaran berbasis internet menjadi alternatif peralihan dampak positif dari pengoptimalan pemanfaatan internet.

Pembelajaran matematika yang dikembangkan dengan media e-learning merupakan pembelajaran matematika menggunakan media intranet yang mengkombinasikan dua atau lebih media. Pengembangan perangkat pembelajaran berbasis kooperatif dengan pendekatan Scientific menjadi inovasi pembelajaran untuk meningkatkan motivasi belajar siswa. Kondisi ini diharapkan mengalihkan dampak negatif pemanfaatan teknologi internet yang selama ini dialami siswa. 
Selain itu, model pembelajaran kooperatif pendekatan scientific dengan media e-learning memiliki ruang komunikasi antara guru dengan siswa dan siswa dengan siswa agar terjadinya interaksi yang baik. Ruang ini memungkinkan tanyajawab guru dengan siswa maupun siswa dengan siswa mengenai materi yang dipelajari atau kesulitan yang dialami siswa. Konsultasi antara guru dengan siswa pun dapat berjalan baik tanpa batasan jarak dan waktu seperti jejaring sosial yang siswa gemari.Kondisi ini diharapkan mengalihkan dampak negatif pemanfaatan teknologi internet bagi siswa.

Penelitian mengenai pengembangan perangkat pembelajaran program linear berbasis model pembelajaran kooperatif pendekatan scientific dengan media $e$ learning, belum pernah dilakukan sebelumnya di SMK Negeri 1 Somba Opu Kabupaten Gowa sehingga perlu adanya penelitian untuk mengetahui bagaimana mengembangkan perangkat pembelajaran program linear berbasis model pembelajaran kooperatif pendekatan scientific dengan media e-learning pada siswa kelas X Multimedia SMK Negeri 1 Somba Opu Kabupaten Gowa.

\section{METODE PENELITIAN}

Jenis penelitian ini adalah penelitian Pengembangan (Development) yang mengembangkan dan mendesain perangkat pembelajaran berbasis e-learning yang meliputi pengembangan perangkat pembelajaran yang terdiri atas Buku Siswa (BS), Rencana Pelaksanaan Pembelajaran (RPP), dan Lembar Kerja Siswa (LKS). Penelitian ini dilaksanakan di SMK I Somba Opu Kab.Gowa, dan subjek dalam penelitian ini adalah siswa kelas X Multimedia berjumlah 30 orang dan dilaksanakan pada semester genap tahun ajaran 2013/2014 melalui tiga tahap yakni tahap persiapan, tahap pelaksanaan dan tahap analisis data.

Adapun cara pengumpulan data yang dilakukan dalam penelitian ini adalah sebagai berikut. (a) Data mengenai aktivitas siswa dan kemampuan guru dalam kegiatan proses pembelajaran, diperoleh dari lembar observasi (pengamatan) aktivitas siswa. (b) Data akhir pembelajaran hasil belajar diperoleh melalui tes. (c) Data mengenai respons siswa terhadap pembelajaran berbasis model pembelajaran kooperatif dengan media $e$ learning melalui angket respons siswa.

Adapun teknik analisi data yang digunakan sebagai berikut: (1) Data hasil penilaian kevalidan perangkat pembelajaran oleh dua validator/ ahli, yaitu orang yang dipandang ahli dalam bidang pendidikan matematika, (2) Data keparaktisan perangkat 
pembelajaran program linear berbasis e-learning setting kooperatif adalah data dari keterlaksanaan pembelajaran program linear secara umum dari dua observer yang dinalisis secara kualitatif. Hasil yang diperoleh pada tiap-tiap pertemuan akan ditentukan berdasarkan nilai rata-rata dari pertemuan pertama sampai pertemuan keempat, (4) Indikator keefektifannya adalah (1) Ketercapaian hasil belajar(2) Aktivitas siswa (3) Respons Siswa

\section{HASIL PENELITIAN DAN PEMBAHASAN}

\section{A. Hasil Analisis Data}

\section{Tahap I : Pendefinisian (Define)}

a. Hasil analisis pendahuluan

Pada awalnya, proses pembelajaran, seringkali guru mendominasi pembelajaran di kelas. Selain itu, masalah dasar yang dihadapi dalam pembelajaran matematika ini dikarenakan (1) Kebanyakan siswa menanyakan apa pentingnya belajar matematika, (2) Kebanyakan siswa maunya belajar sesuai dengan bidang kejuruan yang mereka pilih, (3) Tidak adanya buku siswa serta LKS yang membantu memahami pelajaran. Hal ini merupakan dampak dari penggunaan pembelajaran yang biasa dilakukan oleh guru. Berdasarkan keperluan tersebut maka penulis mengambil alternatif mengenai pembelajaran matematika yang memadukan kemampuan ICT dan matematika dengan mediae-learning.

Dalam penelitian ini, siswa yang digunakan adalah siswa kelas X Multimedia SMK Negeri 1 Somba Opu tahun ajaran 2013-2014.

b. Hasil analisis materi

Pengembangan perangkat pembelajaran matematika dari segi analisis materi ini adalah materi program linear pada pokok bahasan sistem pertidaksamaan linear, model matematika, nilai optimum, garis selidik. Pemilihan materi ini cocok digunakan untuk $e$ learning karena proses penyelesaiannya bisa digunakan dengan bantuan komputer.

c. Hasil analisis tugas

Karakteristik yang digunakan dalam analisis tugas ini sesuai dengan pokok bahasan program linear yang dituangkan dalam bentuk pilihan ganda dan uraian baik dalam LKS maupun KUIS sesuai dengan instrumen yang telah dikategorikan valid, praktis dan efektif. 
d. Perumusan tujuan pembelajaran

Adapun tujuan pembelajaran ini adalah menjawab dari hal yang ingin dicapai dalam pembelajaran program linear berbasis e-learning.

\section{Tahap II : Perancangan (Design)}

Hasil rancangan ini meliputi tahap perancangan seperti.(1) Penyusunan tes, (2) Pemilihan Media Pembelajaran, dan (3) Pemilihan format.

\section{Tahap III : Pengembangan (Develop)}

a. Pengembangan draft awal

Draft awal perangkat pembelajaran ini meliputi Silabus, RPP, Buku Siswa, LKPD dan Tes Hasil Belajar. Silabus ini merupakan pengarah dari pelaksanaan pembelajaran yang nantinya akan dilaksanakan.

1) Validasi perangkat oleh para pakar diikuti dengan revisi

Pembahasan hasil penilaian oleh para ahli. Revisi bahan pengajaran (Instructional revitions) dilakukan melaluiRevisi oleh para ahli.Revisi para ahli terlebih dahulu dilakukan validasi.

b. Uji coba terbatas

Uji coba dilakukan sebanyak lima kali pertemuan mulai tanggal 24 Februari 2014 sampai 2 April 2014. Rancangan awal perangkat pembelajaran dalam hal ini Draft 1 divalidasi oleh ahli dalam bidang pendidikan matematika dengan komputer.

1) Uji Analisis data Kevalidan perangkat pembelajaran

Adapun kriteria yang digunakan sebagai berikut.

Tabel 1. Rangkuman Hasil Validasi Perangkat Pembelajaran

\begin{tabular}{lcc}
\hline \multicolumn{1}{c}{ Sumber } & Skor Rata-rata & Kriteria \\
\hline Silabus & 4.2 & Valid \\
RPP & 4.2 & Valid \\
Buku siswa & 4.2 & Valid \\
LKPD & 4.2 & Valid \\
Tes Hasil Belajar & 4.1 & Valid \\
Media e-learning berbasis & 4.2 & Valid \\
model kooperatif & & \\
pendekatan scientific & & \\
\hline
\end{tabular}

Sumber: Data Primer, Tahun: 2014

Berdasarkan tabel dia atas perangkat pembelajaran tersebut telah layak untuk diujicobakan. Namun, berdasarkan saran dari para ahli masih ada yang perlu 
diperbaiki/ditambah. Setelah dilakukan beberapa revisi berdasarkan masukan dari validator dihasilkan perangkat pembelajaran draft 2, kemudian di ujicobakan.

2) Uji analisis data kepraktisan perangkat pembelajaran

Analisis data kepraktisan perangkat pembelajaran disini adalah analisis data keterlaksanaan perangkat pembelajaran program linear.

3) Uji analisis data keefektifan perangkat pembelajaran

Analisis data Keefektifan perangkat pembelajaran telah dikemukakan pada Bab III dimana dikatakan bahwa perangkat pembelajaran efektif apabila memenuhi tiga indikator yakni

a) Ketercapaian hasil belajar

Ketercapaian hasil belajar itu ditunjang oleh tes hasil belajar yang baik dalam hal ini tuntas. Persentase ketuntasan secara klasikal adalah 93,33\% sehingga hal ini menunjukkan bahwa ketuntasan klasikal telah tercapai.

b) Aktivitas siswa

Tabel 3. Aktivitas Siswa selama Proses Pembelajaran

\begin{tabular}{|c|c|c|c|c|c|c|c|}
\hline \multicolumn{8}{|c|}{ Persentase Waktu Rata-rata Jenis Aktivitas Siswa } \\
\hline \multirow[b]{2}{*}{ No } & \multirow[b]{2}{*}{ Kategori Aktivitas Siswa } & \multicolumn{4}{|c|}{ Pertemuan } & \multirow{2}{*}{$\begin{array}{l}\text { Rata- } \\
\text { rata } \\
(\%)\end{array}$} & \multirow{2}{*}{$\begin{array}{l}\text { Interval } \\
\text { Tolerans } \\
\text { PWI }(\%)\end{array}$} \\
\hline & & I & II & III & IV & & \\
\hline 1 & $\begin{array}{l}\text { Memperhatikan arah/ } \\
\text { informasi yang diberikan } \\
\text { oleh guru }\end{array}$ & 11,67 & 12,78 & 13,89 & 13,89 & 12,92 & $8,9-18,9$ \\
\hline 2 & $\begin{array}{l}\text { Mendownload data yang } \\
\text { dibutuhkan siswa }\end{array}$ & 9,44 & 8,89 & 8,33 & 8,33 & 8,75 & $3,3-13,3$ \\
\hline 3 & $\begin{array}{l}\text { Mengamati dan } \\
\text { mempelajari dengan tekun } \\
\text { materi pembelajaran yang } \\
\text { tertuang pada buku siswa } \\
\text { yang telah diupload pada } e \text { - } \\
\text { learning }\end{array}$ & 8,89 & 8,89 & 8,33 & 8,33 & 8,61 & $6,7-16,7$ \\
\hline 4 & $\begin{array}{l}\text { Aktif bertanya baik kepada } \\
\text { teman maupun kepada guru }\end{array}$ & 13,33 & 13,33 & 14,44 & 13,89 & 13,75 & $7,2-17,2$ \\
\hline 5 & Menjawab/ menanggapi & 12,78 & 14,44 & 13,89 & 13,89 & 13,75 & $7,2-17,2$ \\
\hline
\end{tabular}


Persentase Waktu Rata-rata Jenis Aktivitas Siswa

\begin{tabular}{|c|c|c|c|c|c|c|}
\hline \multirow[b]{2}{*}{ No } & \multirow[b]{2}{*}{ Kategori Aktivitas Siswa } & \multicolumn{3}{|c|}{ Pertemuan } & \multirow{2}{*}{$\begin{array}{c}\text { Rata- } \\
\text { rata } \\
(\%)\end{array}$} & \\
\hline & & I & III & IV & & $\begin{array}{l}\text { Toleransi } \\
\text { PWI (\%) }\end{array}$ \\
\hline
\end{tabular}

pertanyaan atau soal-soal

yang ada di LKS atau kuis

yang telah diupload $(\mathrm{Sc} 3$,

Sc4)

$6 \quad$ Aktif dan tekun

mengerjakan tugas LKS

$\begin{array}{lllllll}\text { atau kuis yang secara } & 31,11 & 32,78 & 33,33 & 33,33 & 32,64 & 28,3- \\ \end{array} \quad \begin{array}{llll}38,3\end{array}$

mandiri baik secara online

maupun offline (Sc4, Sc5)

7 Memberi bantuan

penjelasan kepada teman

kelompok yang

membutuhkan baik secara $\quad 7,22 \quad 7,78 \quad 7,78 \quad 8,33 \quad 7,78 \quad 3,3-13,3$

lisan maupun melalui

fasilitas komunikasi yang

tersedia dalam e-learning

\begin{tabular}{llllllll}
\hline 8 & Kegiatan yang lain & 5,56 & 2,22 & 0,56 & 0,00 & 2,08 & $0-5$ \\
\hline
\end{tabular}

Sumber: Data Primer, Tahun: 2014

Berdasarkan pengamatan aktivitas siswa sebagaimana telah diuraikan di atas, diketahui semua kategori aktivitas siswa yang diamati memenuhi Interval Toleransi PWI (\%) yang ditentukan dan aktivitas siswa berada pada kategori aktif.

c) Respons Siswa

Ada tiga aspek yang menjadi fokus respons siswa terhadap kegiatan pembelajaran berbasis model kooperatif pendekatan scientific dengan media e-learning berdasarkan angket respon yang berikan kepada siswa, di peroleh bahwa respons siswa terhadap perangkat pembelajaran semua berada pada kategori positif. 


\section{Tahap IV : Penyebaran (Disseminates)}

Diseminasi/Penyebaran perangkat pembelajaran hanya bersifat sosialisasi secara terbatas kepada Guru SMK Negeri 1 Somba Opu dengan tujuan untuk mendapatkan masukan, koreksi, saran untuk menyempurnakan produk akhir pengembangan agar siap diadopsi oleh para pengguna produk.

\section{B. Pembahasan Penelitian}

Penelitian ini menggunakan jenis penelitian pengembangan. Menurut Sugiyono (2012) penelitian pengembangan adalah metode penelitian yang digunakan untuk menghasilkan produk tertentu, kemudian menguji keefektifan produk tersebut. Berdasarkan uraian di atas maka dapat disimpulkan bahwasanya pengembangan perangkat pembelajaran merupakan suatu bentuk prosedur yang dimana dilakukan secara terarah dan sistematis untuk menghasilkan suatu perangkat pembelajaran berdasarkan teori pengembangan yang telah ada.

Model pembelajaran kooperatif yang digunakan yaitu tipe STAD. Slavin (Rusman, 2013: 213-214) menyatakan bahwa pada STAD siswa dibagi menjadi kelompok berangotakan 4-5 0rang. Guru menyajikan pelajaran, dan kemudian siswa bekerja dalam tim mereka memastikan bahwa mereka beragam jenis kelamin dan sukunya. Lebih jauh lagi Slavin memaparkan bahwa gagasan utama di belakang STAD adalah memacu siswa agar saling mendorong dan membantu satu sama lain untuk menguasai keterampilan yang diajarkan oleh guru.

Pendekatan ilmiah (Sumardyono, 2013) memberikan kesempatan kepada siswa untuk menemukan, menerapkan ide-ide mereka sendiri, menjadi sadar dan secara sadar menggunakan strategi mereka sendiri untuk belajar. Guru mengembangkan kesempatan belajar kepada siswa untuk meniti anak tangga yang membawa siswa kepemahaman yang lebih tinggi, yang semula dilakukan oleh bantuan guru dan akhirnya menjadikan mereka lebih mandiri. Adapun karasteristik dari pendekatan scientific terdiri dari 5M, yaitu mengamati, menanya, menalar, mencoba dan mengkomunikasikan.

Menurut Siahaan (Wena, 2012: 212-213) setidaknya ada tiga fungsi dari pembelajaran menggunakan media e-learning yaitu sebagai berikut.

1. Sebagai suplemen pembelajaran yang sifatnya pilihan/opsional.

2. E-learning berfungsi sebagai komplemen atau pelengkap

3. Sebagi pengganti atau subtitusi pembelajaran. 
Model pengembangan perangkat yang digunakan dalm penelitian ini yaitu model Four-D yang disarankan oleh Sivasailam, Thiagarajan, Dorothy S, Semmel dan Melvyn I, Semmel. Adapun Tahap-tahap pengembangan 4-D yaitu sebagai berikut.

1. Tahap I Pendefinisian (Define),

2. Tahap II Perancangan (Design),

3. Tahap III Pengembangan (Develop),

4. Tahap IV Penyebaran (Desseminates),

Adapun inti dari penelitian ini adalah sebagai berikut.

1. Kevalidan

Perangkat pembelajaran yang telah disusun termasuk dalam kevalidan. Hal ini dipertegas oleh data yang diperoleh dari hasil validitas tiga orang validator yang ahli dibidang pendidikan matematika dan komputer spesialis Multimedia ini, menunjukkan bahwa rata-rata penilaian atau hasil validasi dari para ahli pada perangkat pembelajaran yang digunakan meliputi RPP, Buku siswa, LKPD, Tes Hasil Belajar, dan media $e$ learningdalam pembelajaran berbasis model kooperatif pendekatan scientific berada pada kategori "Valid" $3,5 \leq \bar{V}<4,5$. Sehingga dapat dikatakan bahwa perangkat pembelajaran berbasis model kooperatif pendekatan scientific dengan media e-learning tersebut telah layak untuk diujicobakan.

\section{Kepraktisan}

Berdasarkan hasil uji coba terbatas yang mengungkapkan nilai kepraktisan diperoleh dari hasil observasi dari para observer yang sebelumnya telah ditunjuk untuk menilai sejauhmana pengelolaan pembelajaran berbasis model pembelajaran kooperatif dengan media e-learning ini telah dilaksanakan di sekolah.

\section{KESIMPULAN DAN SARAN}

\section{A. Kesimpulan}

Proses pengembangan perangkat pembelajaran program linear berbasis model pembelajaran kooperatif pendekatan scientific dengan media e-learning yang valid, praktis dan efektif dilaksanakan dengan empat tahap yaitu: (1) Tahap Pendefinisian, menghasilkan masalah-masalah awal sehingga dilakukan pengembangan perangkat, (2) Tahap Perancangan, menghasilkan rancangan perangkat pembelajaran, (3) Tahap Pengembangan, menghasilkan perangkat pembelajaran yang telah direvisi berdasarkan 
masukan dari para ahli, dan data yang diperoleh dari hasil uji coba, dan (4) Tahap Penyebaran, dilakukan sosialisasi kepada guru-guru yang ada di sekolah penelitian.

Hasil pengembangan perangkat pembelajaran program linear berbasis model pembelajaran kooperatif pendekatan scientific dengan media e-learningyang valid, praktis dan efektif yaitu perangkat pembelajaran secara keseluruhan berada pada rata-rata kevalidan $(\bar{V})$ 4,1 valid dan layak digunakan. Kategorikepraktisan terlaksana dengan baik. Keefektifan diperoleh ketercapaian hasil belajar mencapai standar KKM 70; ratarata aktivitas siswa berada dikategori aktif; dan respon siswa berada pada aspek positif.

\section{B. Saran}

Berdasarkan hasil yang diperoleh dari penelitian ini, maka dapat dikemukakan beberapa saran sebagai berikut:

1. Perangkat pembelajaran yang telah dihasilkan sebaiknya diujicobakan di sekolahsekolah lain.

2. Pada alat bantu media yakni Geogebra, perlu dicari setting skala yang lebih dari angka puluhan atau bahkan ratusan sebab jika soal yang diperoleh di atas dari angka yang terdapat di media tersebut maka medianya tidak dapat digunakan lagi.

3. Program ini sangat bagus diterapkan buat guru-guru dan sangat mengharapkan agar guru-guru di SMK Negeri 1 Somba Opu bisa mengaplikasikan program ini dikelas

4. Bagi calon peneliti yang ingin melanjutkan penelitian ini, disarankan agar mempelajari dengan seksama fasilitas-fasilitas yang ada pada e-learning dan fasilitas komputer benar-benar sesuai yang kita harapkan. 


\section{DAFTAR PUSTAKA}

Nurdin. 2007. Model Pembelajaran Matematika yang Menumbuhkan Metakognitif untuk Menguasai Bahan Ajar. Disertasi.Tidak diterbitkan. Surabaya: Program Pasca Sarjana Universitas Negeri Surabaya.

Rusman. 2013. Model-Model Pembelajaran. Bandung: Raja Grafindo Persada.

Sagala, S. 2009. KemampuanProfesional Guru danTenagaKependidikan. Bandung: Alfabeta.

Santrock, J. W. 2007. PsikologiPendidikan (EdisiKedua). Jakarta: Kencana.

Slavin, R. E. 2005.Cooperative learning: Teori, Riset dan Praktik. Bandung: Nusa Media.

Sugiyono. 2012. Metode Penelitian Pendidikan (Pendekatan Kuantitatif, Kualitatif dan $R$ $\& D$. Bandung: Alfabeta.

Sumardyono. 2013. Pendekatan Ilmiah dalam Pembelajaran Matematika SMK. Makalah pada Diklat LPMP. Makassar.

Suprijono, A. 2012.Cooperative Learning: Teori\&Aplikasi PAIKEM. Yogyakarta: PustakaPelajar.

Sutawijaya. 2011. Pembelajaran Matematika. Jakarta: Universitas Terbuka 